\title{
Advances in endobronchial ablative therapies
}

\author{
Daniel Katzman ${ }^{1}$, Angela Argento ${ }^{2}$ \\ ${ }^{1}$ Division of Pulmonary and Critical Care Medicine, New York Medical College, Valhalla, NY, USA; ${ }^{2}$ Division of Pulmonary and Critical Care \\ Medicine, Feinberg School of Medicine, Northwestern University, Chicago, IL, USA \\ Contributions: (I) Conception and design: All authors; (II) Administrative support: All authors; (III) Provision of study material or patients: None; \\ (IV) Collection and assembly of data: None; (V) Data analysis and interpretation: None; (VI) Manuscript writing: All authors; (VII) Final approval of \\ manuscript: All authors. \\ Correspondence to: Daniel Katzman. Division of Pulmonary and Critical Care Medicine, New York Medical College, Valhalla, NY, USA. \\ Email: daniel.katzman@WMCHealth.org.
}

\begin{abstract}
Endobronchial ablative therapies are standard of care in therapeutic bronchoscopy for management of malignant and non-malignant central airway obstruction and of endobronchial bleeding. In malignant and non-malignant central airway obstruction with endoluminal involvement, a multi-modality bronchoscopic approach combining endobronchial ablative therapies, mechanical debulking, airway dilation, and airway stent placement is often first line treatment. Endobronchial ablative therapies can be utilized in conjunction with chemotherapy, radiation therapy, and surgery to improve quality of life and possibly longterm survival in malignant central airway obstruction. In select cases, endobronchial ablative therapies are treatment options with curative intent for endobronchial carcinoma in situ and early lung cancers. High quality clinical trials directly comparing the efficacy and safety profiles among endobronchial ablative therapies are lacking. Herein, endobronchial ablative therapies are reviewed.
\end{abstract}

Keywords: Endobronchial ablative therapy; cryotherapy; electrocautery; argon plasma coagulation (APC); light amplification by stimulated emission of radiation (LASER); endobronchial brachytherapy; photodynamic therapy

Received: 17 February 2020; Accepted: 01 June 2020; Published: 10 July 2021.

doi: $10.21037 /$ shc-20-47

View this article at: http://dx.doi.org/10.21037/shc-20-47

\section{Introduction}

Endobronchial ablative therapies are standard of care in therapeutic bronchoscopy for management of malignant and non-malignant central airway obstruction and of endobronchial bleeding. In the setting of hemoptysis in lung cancer patients, the American College of Chest Physicians recommends bronchoscopy with endobronchial ablative therapies for the management of any visible central airway lesions (1). In malignant and non-malignant central airway obstruction with endoluminal involvement, a multimodality bronchoscopic approach combining endobronchial ablative therapies, mechanical debulking, airway dilation, and airway stent placement is often first line treatment. For example, endobronchial ablative therapies can be utilized for initial devascularization of an endobronchial tumor prior to mechanical tumor debulking and/or tumor photoresection with endobronchial ablative therapies. Afterwards, coagulation and destruction of the residual tumor base can be performed with endobronchial ablative therapies $(2,3)$. In the multi-center AQuIRE bronchoscopy registry of over 1,000 bronchoscopy cases for treatment of malignant airway obstruction, cryotherapy, electrocautery, argon plasma coagulation (APC), and laser were used in $8 \%$, $21.3 \%, 35.2 \%$, and $23.5 \%$ of cases, respectively (4).

Endobronchial ablative therapies can be utilized in conjunction with chemotherapy, radiation therapy, and surgery to improve quality of life and possibly longterm survival in malignant central airway obstruction (5). Endobronchial ablative therapies are effective for relieving dyspnea, cough, wheezing, hemoptysis, and/or postobstructive atelectasis and pneumonia. In select cases, endobronchial ablative therapies are treatment options with curative intent for endobronchial carcinoma in situ 
Table 1 Summary comparison of endobronchial ablative therapies

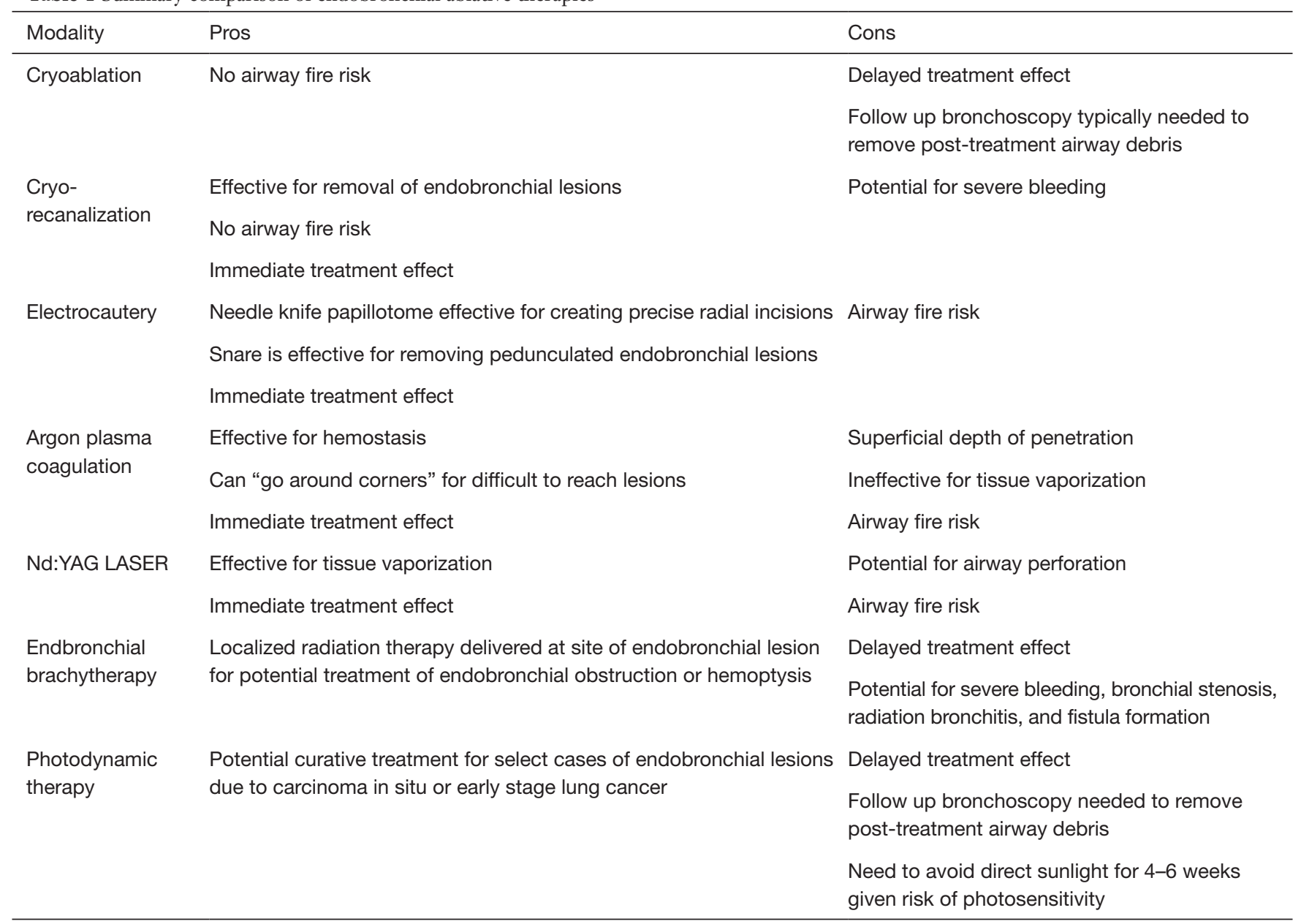

and early lung cancers. The American College of Chest Physicians recommends endobronchial ablative therapy with photodynamic therapy, electrocautery, brachytherapy, or cryotherapy for superficial limited mucosal lung cancer in the central airways when patients are not candidates for surgical resection (6). High quality clinical trials directly comparing the efficacy and safety profiles among endobronchial ablative therapies are lacking. Herein, endobronchial ablative therapies are compared and reviewed (Table 1).

\section{Cryotherapy}

In cryotherapy, extremely cold temperatures are administered to target tissue for therapeutic effect; 1.9-mm diameter and 2.4-mm diameter flexible cryoprobe (Erbe USA, Inc., Marietta, GA) are approved for use in the
United States by the Food and Drug Administration (7). In the cryoprobe system, a cryogen is stored in a highly pressurized liquid state. Based on the Joule-Thomson effect, the compressed cryogen is opened to an expansion chamber and is converted to a gaseous state at atmospheric pressure (7). This creates freezing temperatures at the metallic tip of the cryoprobe. The cryoprobe metallic tip is then placed in direct contact with target tissue (Figure 1). The most common cryogen is nitrous oxide, which cools the cryoprobe tip to -89 degrees Celsius. In comparison to electrocautery and laser therapy, there is no airway fire risk, and therefore, the $\mathrm{FiO}_{2}$ does not need to be lowered to less than 0.4. Cryotherapy is utilized in therapeutic bronchoscopy in the forms of cryoablation, cryorecanalization/cryo-debulking, and cryo-extraction, which are described below.

In cryoablation, a freeze phase followed by a passive thaw 


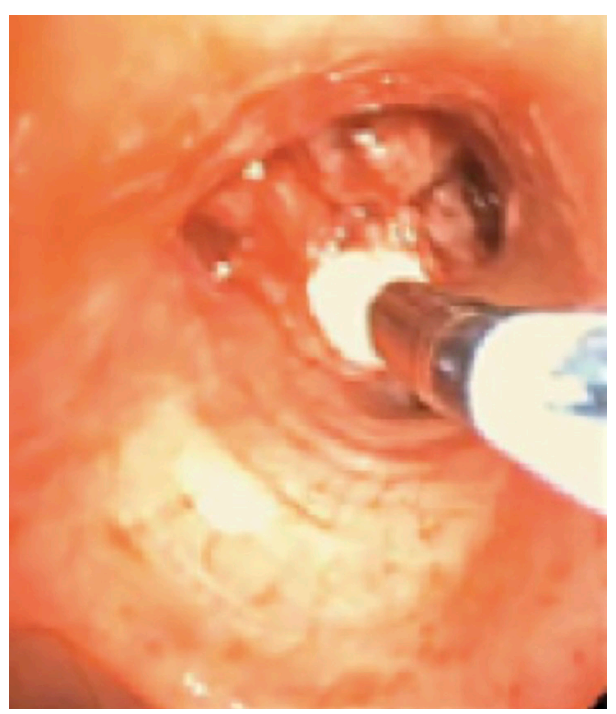

Figure 1 The metallic tip of the flexible cryoprobe is in direct contact with the target endobronchial tumor. In cryotherapy, the flexible cryoprobe is activated to administer a freeze phase.

phase is administered to target tissue. Cryoablation causes tissue necrosis and sloughing in a delayed fashion over 48-72 hours. As a result, a follow up bronchoscopy is commonly needed to remove necrotic debris from the airway (8). Because of the delayed therapeutic effect, cryoablation is not an appropriate treatment option when emergent airway interventions are needed. Cryoablation causes tissue destruction and necrosis through multiple mechanisms. Extracellular fluid freezes leading to water shifts and cell dehydration. Intracellular ice crystals form, damaging cell membranes and organelles. Additionally, microvascular stasis and thrombosis and immunological responses occur $(9,10)$. Because tissue destruction is dependent on the water content of the target tissue, tissue with low water content such as cartilage is relatively resistant to cryoablation. Potential complications of cryoablation include respiratory distress due to airway obstruction from necrotic debris, bleeding, and airway perforation. In a retrospective review of 521 patients with malignant airway obstruction treated with cryoablation, dyspnea and hemoptysis were improved after treatment in $59.2 \%$ and $76.4 \%$ of cases, respectively. No major complications were reported. Post-procedure transient respiratory distress occurred in 3\% of cases and hemoptysis in $4 \%$ of cases (8).

In contrast to cryoablation, cryo-recanalization/cryodebulking and cryo-extraction utilize the flexible cryoprobe to immediately remove target endoluminal tissue. A freeze phase of approximately $5-15$ seconds is administered to target tissue. This is not followed by a thawing phase. Instead, the bronchoscope and flexible cryoprobe with adherent frozen target tissue are immediately removed from the airway en bloc. This can be repeated numerous times until the desired effect is achieved. In single center retrospective studies, cryo-recanalization and cryoextraction are effective techniques for tumor debulking and for removal of blood clots and mucus plugs from the central airways (11-13). In a retrospective review of 156 patients with malignant airway obstruction treated primarily with cryo-recanalization, airway patency was achieved in $95 \%$ of patients. Significant complications, however, occurred in $11 \%$ of patients including severe bleeding, airway injury, respiratory distress, and hemodynamic instability (11). Caution is needed in the setting of highly vascularized tumors, which are at risk for difficult to control bleeding when utilizing cryo-recanalization.

An alternative cryotherapy delivery system to the flexible cryoprobe is spray cryotherapy. In spray cryotherapy, liquid nitrogen administered to the target tissue via a catheter, which is not in direct contact with the target tissue. The liquid nitrogen at -196 degrees Celsius causes rapid freezing of the target tissue (14). In a case series of spray cryotherapy for treatment of malignant airway obstruction in 80 patients (114 treatments), airway patency was achieved in 79 patients. The intraoperative complication rate, however, was $19 \%$ including two intra-operative deaths associated with bradycardia and three pneumothoraces (15). Larger studies are needed to further evaluate the effectiveness and safety profile of spray cryotherapy.

\section{Electrocautery}

In electrocautery, electric current generates heat for therapeutic effect. Electrical safety precautions are needed with electrocautery. This includes lowering the $\mathrm{FiO}_{2}$ to below 0.4 to minimize the risk of an airway fire and applying a grounding pad to the patient. The coagulation effect of electrocautery occurs at $>40$ degrees Celsius. The cutting effect of electrocautery occurs at a temperature of $>300$ degrees Celsius due to tissue vaporization $(16,17)$. Bronchoscopic electrocautery tools commonly used include the electrocautery snare, needle knife, and probe. The electrocautery snare is an effective tool for removing pedunculated endobronchial lesions, which are attached to by a stalk to the bronchial wall. The snare is lassoed 


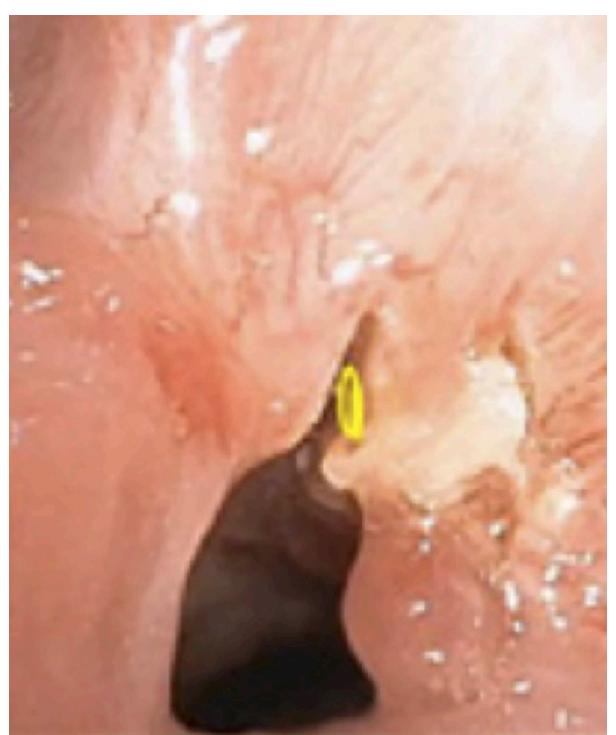

Figure 2 Radial incision of a post-intubation sub-glottic stenosis (12 o'clock position or yellow mark) was performed with an electrocautery needle knife.

around the lesion's stalk, and electrocautery is used to cut and detach the endobronchial lesion from the bronchial wall (16).

The electrocautery needle knife papillotome is an effective tool to create precise radial incisions. For example, precise radial incisions can be made prior to airway dilation of simple, web-like sub-glottic or tracheal stenoses (Figure 2). As a result, airway dilation can occur in a controlled fashion. This potentially prevents irregular airway tears from developing during airway dilation, which could lead to airway injury (18). In a small retrospective study, the combination of electrocautery needle knife with tracheal balloon dilation was more effective than balloon dilation alone for the management of post-intubation or post-tracheostomy tracheal stenosis, particularly for web-like stenosis (19). Another commonly used tool is the electrocautery probe. The electrocautery probe is placed in direct contact with the target lesion for tissue destruction. In retrospective studies of electrocautery as an endobronchial ablative therapy for central airway obstruction, electrocautery has been shown to be safe, effective, and a potentially cost-effective alternative to laser therapy $(20,21)$. Potential complications of electrocautery include bleeding, airway fire, and airway perforation. In a retrospective review of 117 patients with benign or malignant airway obstructions treated primarily with electrocautery, there was only one serious complication related to an aspiration event (20). Recently, a novel electrosurgical device called Core Cath (Medtronic) is available, which combines electrocautery with simultaneous continuous suction for removal of smoke and/or blood. Clinical studies of the Core Cath's effectiveness and safety profile in tumor debulking are currently needed (22).

\section{APC}

APC is a non-contact application of electrosurgery. Argon plasma is created when argon gas becomes ionized by a tungsten electrode located at the tip of the catheter (23). The generated electrical current flows following the path of least resistance causing coagulative necrosis. As a result of following the path of least resistance, the electrical current may reach lesions located laterally to the probe meaning it can "go around corners" for difficult to reach lesions. APC has excellent properties of hemostasis. In a case series of over 50 patients with endobronchial bleeding, APC was $100 \%$ effective for immediate resolution of hemoptysis. Furthermore, hemoptysis did not re-occur over a mean follow up of over 3 months. There were no procedure related complications (24). The depth of penetration of APC is only $2-3 \mathrm{~mm}$. Consequently, APC is ineffective for tissue vaporization (24). Gas embolism is a rare, but lifethreatening potential complication of APC. In a case series of three patients who developed gas embolism with cardiac collapse following APC, gas flow rates were greater than or equal to $1.0 \mathrm{~L} / \mathrm{min}$. The use of the lowest possible gas flow rate is recommended to prevent gas embolism (25). Typical initial settings are a gas flow rate of $0.8 \mathrm{~L} / \mathrm{min}$ and a power of 20 to 30 watts. When using APC, electrical safety is needed, and an $\mathrm{FiO}_{2}$ below 0.4 is needed to minimize the risk of an airway fire.

\section{Light amplification by stimulated emission of radiation (LASER)}

Laser light consists of photons of a single wavelength (monochromatic), which travel in parallel (coherence), and in the same direction (collimation) (26). Target tissue absorbs the laser beam generating heat. The generation of heat leads to photocoagulation and tissue vaporization (Figure 3A,B). The Nd:YAG (neodymium-yttrium, aluminum, garnet) laser is currently the most commonly utilized laser in therapeutic bronchoscopy (26). Prior to the $\mathrm{Nd}$ :YAG laser, $\mathrm{CO}_{2}$ and argon lasers were available. $\mathrm{CO}_{2}$ 

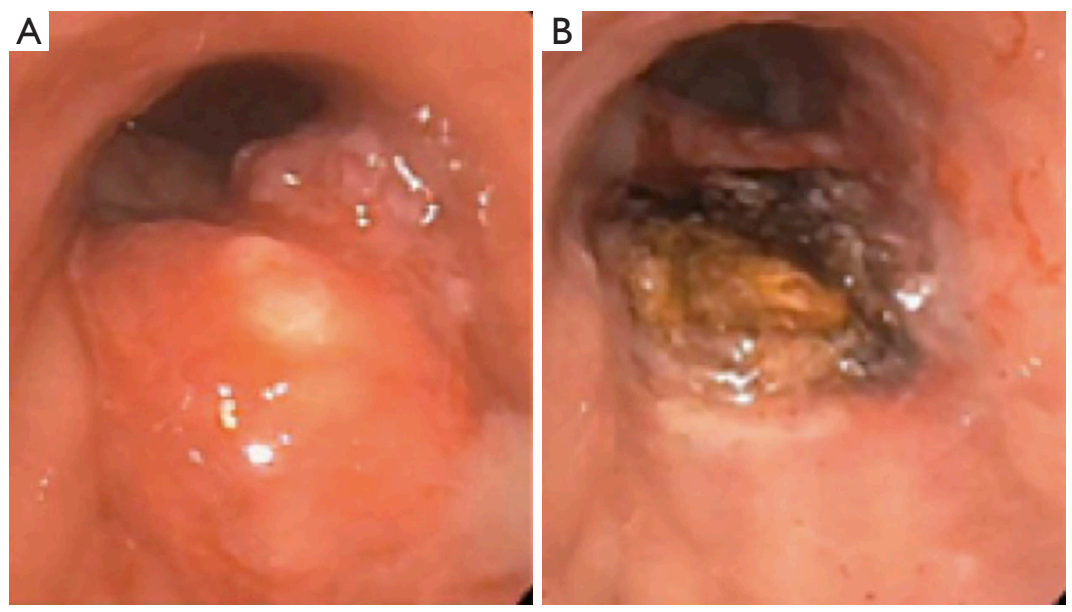

Figures 3 Endobronchial tumor in distal left mainstem bronchus before (A) and after (B) treatment with Nd:YAP laser.

laser has a wavelength of $10,600 \mathrm{~nm}$ and a highly effective cutting effect, but has a shallow depth of penetration of $<1 \mathrm{~mm}$ (27). $\mathrm{CO}_{2}$ laser cannot be carried on a quartz monofilament, and therefore, requires rigid bronchoscopy. Argon laser has a wavelength of 488-514 nm, and can be carried on a quartz monofilament. Due to strong absorption by hemoglobin, however, tissue penetration is limited to only 1-2 mm (23).

Nd:YAG laser has a wavelength of $1,064 \mathrm{~nm}$, which creates an invisible, infrared laser beam. Nd:YAG laser is carried on a quartz monofilament and can be used with a flexible bronchoscope. In comparison to the $\mathrm{CO}_{2}$ laser, the Nd:YAG laser has a depth of penetration of up to $10 \mathrm{~mm}$, but is less precise (23). In a case series of 2,610 Nd:YAG laser resections for treatment of malignant airway obstruction in over 1,800 patients, immediate airway patency was achieved in $93 \%$ of cases (3). Airway bleeding, pneumothoraces, and respiratory failure occurred in 19 , 8 , and 15 cases, respectively (3). Another common laser in bronchoscopy is the Nd:YAP (neodymium: yttriumaluminum-perovskite) laser. The Nd:YAP laser has a wavelength of $1,340 \mathrm{~nm}$. The higher wavelength of the Nd:YAP laser compared to the Nd:YAG laser may lead to theoretical improvements in devascularization and coagulation (26). Additionally, the KTP (potassium titanyl phosphate) laser is also available in bronchoscopy. The KTP laser has a wavelength of $532 \mathrm{~nm}$, and emits a visible green light. Compared to Nd:YAG and Nd:YAP lasers, the KTP laser has a lower depth of penetration and an inferior coagulative effect. Although rarely utilized in adults, the KTP laser is used in the management of tracheal hemangiomas and tracheoesophageal fistulas in pediatric cases (26).

Potential complications with laser therapy include airway perforation, airway fire, and bleeding. Additionally, there have been rare case reports of gas embolism (28). The risk of gas embolism may be minimized in the setting of utilizing a non-contact mode of laser therapy (28). When using laser therapy, the patient and staff should be wearing eye protective goggles. The $\mathrm{FiO}_{2}$ should be lowered to below 0.40 and caution is needed in the presence of endotracheal tubes, silicone, and hybrid airway stents to minimize the risk of an airway fire. The laser beam needs to be directed in parallel to the airway walls to minimize the risk of an airway perforation (26).

\section{Endobronchial brachytherapy}

In endobronchial brachytherapy, localized radiation therapy is delivered at the site of target endobronchial lesion. Iridium-192 is the typical radiation source. Gamma rays from the radiation source cause direct damage to DNA. This leads to cellular apoptosis and decreased proliferation. Brachytherapy has a delayed effect. Initial effects occur can be recognized approximately 1 week post-treatment, and maximal effect is reached approximately 3 weeks posttreatment (29). According to guidelines by the American Society for Radiation Oncology, palliative endobronchial brachytherapy can be considered in combination with thoracic external beam radiation in the setting of endobronchial disease with lung collapse. Additionally, endobronchial brachytherapy can be considered in patients 
previously treated with thoracic external beam radiation who have an endobronchial lesion causing obstruction or hemoptysis (30). In a randomized control trial of nonsmall cell lung cancer with central airway tumors, external beam radiation with endobronchial brachytherapy had a higher rate of lung re-expansion compared to external beam radiation alone (31). A 2012 Cochrane Review metaanalysis of 14 randomized control trials of endobronchial brachytherapy in advanced non-small cell lung cancer, however, did not find evidence to support the combination of endobronchial brachytherapy with external beam radiation over external beam radiation alone (32).

In endobronchial brachytherapy, the brachytherapy catheter is placed under bronchoscopic guidance. The catheter may be placed intra-nasally or through an existing endotracheal tube alongside the bronchoscope. The distal tip of the catheter is positioned approximately $2 \mathrm{~cm}$ beyond the distal border of the target endbronchial lesion $(22,33)$. Radiation can be delivered with low, intermediate, or high dose rates. Low dose rate consists of a single session lasting up to 3 days at a rate of $<2 \mathrm{~Gy} / \mathrm{hour}$. Intermediate dose rate is approximately $2-10 \mathrm{~Gy} /$ hour. High dose rate consists of rate is $>12$ Gy/hour. A typical high dose regimen consists of an average of three fractions over weekly intervals. The duration of each fraction is approximately between 3 and 30 minutes, and high dose rate brachytherapy can be performed on an outpatient basis (23). There is currently only limited available evidence comparing endobronchial brachytherapy dosages and rates (33). In a case series of over 100 lung cancer patients with endobronchial involvement treated with high dose rate endobronchial brachytherapy, failure to achieve local control was associated with tumor length $>2 \mathrm{~cm}$, endobronchial obstruction $>25 \%$, and previous endoscopic treatment (34). Complications of endobronchial brachytherapy include hemoptysis (including life-threatening), bronchial stenosis, radiation bronchitis, and fistula formation $(22,23,35)$. In 342 patients with endobronchial tumors treated with endobronchial therapy, the rate of complications was high including $7 \%$ rate of fatal hemoptysis and $11 \%$ rate of radiation bronchitis and stenosis (35).

\section{Photodynamic therapy}

In photodynamic therapy (PDT), a porphyrin based photosensitizer, Photofrin (porfimer sodium), is administered intravenously at a recommended dose of $2 \mathrm{mg} / \mathrm{kg}$ approximately 48 hours prior to the initial bronchoscopy.
The photosensitizer is retained by the malignant cells. During the initial bronchoscopy with illumination, a non-thermal laser beam with a wavelength of $630 \mathrm{~nm}$ is focused on the target pre-sensitized endobronchial tumor to activate the Photofrin $(23,29)$. Activation causes a type II photosensitized oxidation reaction with the generation of reactive oxygen species (predominately singlet oxygen) leading to cytotoxicity and tissue necrosis. The depth of tissue destruction is approximately $5-10 \mathrm{~mm}$ (36). A follow up bronchoscopy approximately 48 hours after laser activation is needed to remove any post-treatment necrotic debris and tissue sloughing. If residual tumor is present, re-illumination can be performed for additional treatment followed by an additional follow up bronchoscopy a few days later $(23,29)$. Patients treated with PDT are instructed to avoid direct sunlight for four to six weeks in order to minimize the risk of photosensitivity.

PDT is a palliative treatment option for malignant airway obstruction and endobronchial bleeding.

In a retrospective study of 133 patients undergoing over 500 bronchoscopies, PDT was selected as the primary treatment modality for patients with either highly vascular/ bloody central tumors located in areas of airways deemed not amenable to photoresection with ND:YAG laser therapy or distal endobronchial tumors. Post-treatment, distal airway patency was achieved in majority of cases (81\%). There were significant improvements in dyspnea (74\%) and hemoptysis (99\%). Post-procedure complications included re-intubations in four patients for respiratory distress (two requiring emergent removal of necrotic debris for relief of airway obstruction), hemoptysis in two patients, and photosensitivity in four patients (37).

In select cases of endobronchial lesions due to carcinoma in situ or early stage lung cancer, PDT with curative intent is a potential treatment option. Early stage central airway lung cancer has been defined by the Japan Lung Cancer Society as a localized endobronchial squamous cell carcinoma (located in sub-segmental airways or more proximal), which are $<2 \mathrm{~cm}$ in greatest dimension and have distinct margins on bronchoscopic examination $(38,39)$. Radial endobronchial ultrasound is an effective tool to assess for depth of tumor invasion and for tumor invasion beyond the cartilaginous wall (indicating an invasive squamous carcinoma) (40). Alternatively to PDT, treatment of early stage central airway lung cancer has been performed with cryotherapy, brachytherapy, and electrocautery. There are no clinical trials directly comparing the effectiveness of PDT to other endobronchial ablative therapies for this 
indication. Clinical experience with other endobronchial ablative therapies compared to PDT is sparse $(6,34,41,42)$.

In a retrospective review of 264 early stage central airway lung cancers in 204 patients in Japan, initial complete response rates were $94.6 \%$ and $93.5 \%$ for endobronchial lesions $<0.5 \mathrm{~cm}$ and $0.5-1 \mathrm{~cm}$, respectively. Initial complete response rates fell to $44.1 \%$ for endobronchial lesions $>2 \mathrm{~cm}$. Overall, reoccurrences after a complete response occurred in only $11.6 \%$ of endobronchial tumors. In the majority of the cases, the photosensitizer was Photofrin. A newer photosensitizer, Laserphyrin (mono-L-aspartyl chlorine e6, NPe6), has been available in Japan since 2004 , and was used in the treatment of 40 of the 264 endobronchial lesions (43). There have associations with fewer adverse photosensitivity reactions with Laserphyrin compared to Photofrin. Larger, multi-center studies, however, are needed to further evaluate the effectiveness and safety profile of Laserphyrin (6). Furthermore, the future development of newer photosensitizers may have the potential for improved efficacy for the treatment of endobronchial tumors $>1 \mathrm{~cm} \mathrm{(38).}$

\section{Conclusions}

Endobronchial ablative therapies are effective for relieving both benign and malignant airway obstructions, managing endobronchial bleeding, and can be utilized with curative intent in in select cases of early lung cancer. The combination of endobronchial ablative therapies alone and in combination with chemotherapy, radiation, and surgery has the potential to improve quality of life and long-term survival.

\section{Acknowledgments}

Funding: None.

\section{Footnote}

Provenance and Peer Review: This article was commissioned by the Guest Editors (Kyle Hogarth and Jonathan Kurman) for the series "Interventional pulmonology and advanced bronchoscopy" published in Shangbai Chest. The article was sent for external peer review organized by the Guest Editors and the editorial office.

Conflicts of Interest: Both authors have completed the ICMJE uniform disclosure form (available at http://dx.doi. org/10.21037/shc-20-47). The series "Interventional pulmonology and advanced bronchoscopy" was commissioned by the editorial office without any funding or sponsorship. The authors have no other conflicts of interest to declare.

Ethical Statement: The authors are accountable for all aspects of the work in ensuring that questions related to the accuracy or integrity of any part of the work are appropriately investigated and resolved.

Open Access Statement: This is an Open Access article distributed in accordance with the Creative Commons Attribution-NonCommercial-NoDerivs 4.0 International License (CC BY-NC-ND 4.0), which permits the noncommercial replication and distribution of the article with the strict proviso that no changes or edits are made and the original work is properly cited (including links to both the formal publication through the relevant DOI and the license). See: https://creativecommons.org/licenses/by-nc-nd/4.0/.

\section{References}

1. Simoff MJ, Lally B, Slade MG, et al. Symptom management in patients with lung cancer: Diagnosis and management of lung cancer, 3rd ed: American College of Chest Physicians evidence-based clinical practice guidelines. Chest 2013;143:e455S-e497S.

2. Flannery A, Daneshvar C, Dutau H, et al. The Art of Rigid Bronchoscopy and Airway Stenting. Clin Chest Med 2018;39:149-67.

3. Cavaliere, S, Venuta F, Foccoli P, et al. Endoscopic treatment of malignant airway obstructions in 2,008 patients. Chest 1996;110:1536-42.

4. Ost DE, Ernst A, Grosu HB, et al. Therapeutic bronchoscopy for malignant central airway obstruction: success rates and impact on dyspnea and quality of life. Chest 2015;147:1282-98.

5. Ong P, Grosu HB, Debiane L, et al. Long-term qualityadjusted survival following therapeutic bronchoscopy for malignant central airway obstruction. Thorax 2019;74:141-56.

6. Wisnivesky JP, Yung RC, Mathur PN, et al. Diagnosis and treatment of bronchial intraepithelial neoplasia and early lung cancer of the central airways: Diagnosis and management of lung cancer, 3rd ed: American College of Chest Physicians evidence-based clinical practice guidelines. Chest 2013;143:e263S-e277S. 
7. DiBardino DM, Lanfranco AR, Haas AR. Bronchoscopic Cryotherapy. Clinical Applications of the Cryoprobe, Cryospray, and Cryoadhesion. Ann Am Thorac Soc 2016;13:1405-15.

8. Maiwand MO, Asimakopoulos G. Cryosurgery for lung cancer: clinical results and technical aspects. Technol Cancer Res Treat 2004;3:143-50.

9. Chu KF, Dupuy DE. Thermal ablation of tumours: biological mechanisms and advances in therapy. Nat Rev Cancer 2014;14:199-208.

10. Gage AA, Baust J. Mechanisms of tissue injury in cryosurgery. Cryobiology 1998;37:171-86.

11. Inaty H, Folch $\mathrm{E}$, Berger R, et al. Unimodality and Multimodality Cryodebridement for Airway Obstruction. A Single-Center Experience with Safety and Efficacy. Ann Am Thorac Soc 2016;13:856-61.

12. Schumann C, Hetzel M, Babiak AJ, et al. Endobronchial tumor debulking with a flexible cryoprobe for immediate treatment of malignant stenosis. J Thorac Cardiovasc Surg 2010;139:997-1000.

13. Sriratanaviriyakul N, Lam F, Morrisey BM, et al. Safety and Clinical Utility of Flexible Bronchoscopic Cryoextraction in Patients With Non-neoplasm Tracheobronchial Obstruction: A Retrospective Chart Review. J Bronchology Interv Pulmonol 2015;22:288-93.

14. Bilaçeroğlu S. Endobronchial Ablative Therapies. Clin Chest Med 2018;39:139-48.

15. Finley DJ, Dycoco J, Sarkar S, et al. Airway spray cryotherapy: initial outcomes from a multiinstitutional registry. Ann Thorac Surg 2012;94:199-203; discussion 203-4.

16. Mahajan AK, Ibrahim O, Perez R, et al. Electrosurgical and Laser Therapy Tools for the Treatment of Malignant Central Airway Obstructions. Chest 2020;157:446-53.

17. Chaddha U, Hogarth DK, Murgu S. Bronchoscopic Ablative Therapies for Malignant Central Airway Obstruction and Peripheral Lung Tumors. Ann Am Thorac Soc 2019;16:1220-9.

18. Solly WR, O'Connell RJ, Lee HJ, et al. Diagnosis of idiopathic tracheal stenosis and treatment with papillotome electrocautery and balloon bronchoplasty. Respir Care 2011;56:1617-20.

19. Bo L, Li C, Chen M, et al. Application of Electrocautery Needle Knife Combined with Balloon Dilatation versus Balloon Dilatation in the Treatment of Tracheal Fibrotic Scar Stenosis. Respiration 2018;95:182-7.

20. Wahidi MM, Unroe MA, Adlakha N, et al. The use of electrocautery as the primary ablation modality for malignant and benign airway obstruction. J Thorac Oncol 2011;6:1516-20.

21. Boxem T, Muller M, Venmans B, et al. Nd-YAG laser vs bronchoscopic electrocautery for palliation of symptomatic airway obstruction: a cost-effectiveness study. Chest 1999;116:1108-12.

22. Shepherd RW, Radchenko C. Bronchoscopic ablation techniques in the management of lung cancer. Ann Transl Med 2019;7:362.

23. Ernst A, Feller-Kopman D, Becker HD, et al. Central airway obstruction. Am J Respir Crit Care Med 2004;169:1278-97.

24. Morice RC, Ece T, Ece F, et al. Endobronchial argon plasma coagulation for treatment of hemoptysis and neoplastic airway obstruction. Chest 2001;119:781-7.

25. Reddy C, Majid A, Michaud G, et al. Gas embolism following bronchoscopic argon plasma coagulation: a case series. Chest 2008;134:1066-9.

26. Khemasuwan D, Mehta AC, Wang KP. Past, present, and future of endobronchial laser photoresection. J Thorac Dis 2015;7:S380-8.

27. Lee P, Kupeli E, Mehta AC. Therapeutic bronchoscopy in lung cancer. Laser therapy, electrocautery, brachytherapy, stents, and photodynamic therapy. Clin Chest Med 2002;23:241-56.

28. Tellides G, Ugurlu BS, Kim RW, et al. Pathogenesis of systemic air embolism during bronchoscopic Nd:YAG laser operations. Ann Thorac Surg 1998;65:930-4.

29. Vergnon JM, Huber RM, Moghissi K. Place of cryotherapy, brachytherapy and photodynamic therapy in therapeutic bronchoscopy of lung cancers. Eur Respir J 2006;28:200-18.

30. Rodrigues G, Videtic GM, Sur R, et al. Palliative thoracic radiotherapy in lung cancer: An American Society for Radiation Oncology evidence-based clinical practice guideline. Pract Radiat Oncol 2011;1:60-71.

31. Langendijk H, de Jong J, Tjwa M, et al. External irradiation versus external irradiation plus endobronchial brachytherapy in inoperable non-small cell lung cancer: a prospective randomized study. Radiother Oncol 2001;58:257-68.

32. Reveiz L, Rueda JR, Cardona AF. Palliative endobronchial brachytherapy for non-small cell lung cancer. Cochrane Database Syst Rev 2012;12:CD004284.

33. Stewart A, Parashar B, Patel M, et al. American Brachytherapy Society consensus guidelines for thoracic brachytherapy for lung cancer. Brachytherapy 2016;15:1-11. 
34. Hennequin C, Bleichner O, Tredaniel J, et al. Longterm results of endobronchial brachytherapy: A curative treatment? Int J Radiat Oncol Biol Phys 2007;67:425-30.

35. Speiser BL, Spratling L. Remote afterloading brachytherapy for the local control of endobronchial carcinoma. Int J Radiat Oncol Biol Phys 1993;25:579-87.

36. Dougherty TJ, Marcus SL. Photodynamic therapy. Eur J Cancer 1992;28A:1734-42.

37. Minnich DJ, Bryant AS, Dooley A, et al. Photodynamic laser therapy for lesions in the airway. Ann Thorac Surg 2010;89:1744-8; discussion 1748-9.

38. Ikeda N, Usuda J, Maehara S. Photodynamic therapy for central-type early-stage lung cancer. Gen Thorac Cardiovasc Surg 2020;68:679-83.

39. Ikeda N, Hayashi A, Iwasaki K, et al. Comprehensive diagnostic bronchoscopy of central type early stage lung

doi: $10.21037 /$ shc-20-47

Cite this article as: Katzman D, Argento A. Advances in endobronchial ablative therapies. Shanghai Chest 2021;5:23. cancer. Lung Cancer 2007;56:295-302.

40. Miyazu Y, Miyazawa T, Kurimoto N, et al. Endobronchial ultrasonography in the assessment of centrally located early-stage lung cancer before photodynamic therapy. Am J Respir Crit Care Med 2002;165:832-7.

41. Deygas N, Froudarakis M, Ozenne G, et al. Cryotherapy in early superficial bronchogenic carcinoma. Chest 2001;120:26-31.

42. van Boxem TJ, Venmans BJ, Schramel FM, et al. Radiographically occult lung cancer treated with fibreoptic bronchoscopic electrocautery: a pilot study of a simple and inexpensive technique. Eur Respir J 1998;11:169-72.

43. Kato H, Usuda J, Okunaka T, et al. Basic and clinical research on photodynamic therapy at Tokyo Medical University Hospital. Lasers Surg Med 2006;38:371-5. 